\title{
Stabilisation of the infected spine
}

\author{
R M REDFERN, JOHN MILES, A J BANKS, * E DERVIN†
}

From the Mersey Regional Department of Medical and Surgical Neurology, Walton Hospital, Liverpool, the Department of Orthopaedics, Bolton General Infirmary, Bolton* and the Department of Aeronautical and Mechanical Engineering, Salford University, Manchester $\dagger$

SUMMARY A metal stabilising rod was inserted at the time of surgical drainage of the abscess in six patients with spinal instability secondary to vertebral osteomyelitis. The procedure enabled early postoperative mobilisation to be undertaken in five patients. All cases obtained immediate relief of pain. One case of delayed wound healing occurred but no late recurrent infections were encountered after discontinuing antibiotic therapy. The technique was employed in cases of pyogenic as well as tuberculous spinal osteomyelitis.

Vertebral osteomyelitis is always associated with pain which may be related to periosteal inflammation or distortion, or to radiculopathy caused by bone collapse or angulation. In acute pyogenic osteomyelitis rapid resolution is to be expected following surgical drainage and chemotherapy, but pain due to instability may persist and dominate the clinical picture. In a previous report ${ }^{1}$ we discussed the benefits of the Banks Dervin rod in relieving pain and facilitating early mobilisation of patients with instability pain due to metastatic spinal malignancy. We now report the use of this implanted metal stabilising rod in six patients presenting with infective conditions of the spine and discuss the advantages conferred by the technique.

\section{Case reports}

Case 1 A 20 year old man presented with thoracic back pain and progressive paraparesis. Angulation and collapse at $\mathrm{T} 7$ with a paravertebral mass, and an extradural block revealed by myelography, were demonstrated. Tuberculosis was diagnosed clinically but despite chemotherapy he developed a flaccid paraplegia with a sensory level at T10. Through a right thoracotomy a paravertebral abscess was drained and lateral vertebral decompression with rib graft fusion was performed. Because our experience of combined anterior and posterior stabilisation for instability due to spinal malignancy had been favourable ${ }^{1}$ a Banks Dervin rod was inserted to facilitate early mobilisation. Mycobacterium tuberculosis was cultured from the abscess. Neurological recovery was complete at 6 months when radiographs showed satisfactory position of the prosthesis and a normal spinal

Address for reprint requests: Mr R M Redfern, Walton Hospital, Rice Lane, Liverpool L9 IAE, UK.

Received 2 October 1987 and in revised form 19 January 1988. Accepted 23 February 1988 curvature (fig 1). Chemotherapy was discontinued after 2 years and the patient was symptom-free when last reviewed 6 months later.

Case 2 A 60 year old labourer with recent haemoptysis and back pain presented with painless retention of urine. He was gravely ill from respiratory disease. Any movement caused severe pain arising from a tender, visibly unstable gibbus in the mid-thoracic region. He had a flaccid paraparesis and a sensory level at T9 with no sacral sparing. Radiographs showed collapse at T8, obliteration of the T8/9 disc space and a paravertebral mass. Through a right thoracotomy a paravertebral abscess was drained and anterior decompression with rib graft interbody fusion was undertaken. In view of his parlous general condition posterior fixation with a Banks Dervin rod was performed. Escherichia coli was grown from blood, sputum and the abscess. Tubercle bacilli were not identified or cultured but in view of the suspicion antituberculous agents were added in addition to antibiotics active against $E$. coli. Neurological recovery was slow but at 4 months the patient walked using a Zimmer frame. He remained catheterised because of prostatic hypertrophy. Six months after operation he died from unrelated cardiac failure, having been off all antibiotics for 2 months with no sign of recurrent infection. He had been pain-free from the time of surgery.

Case 3 During investigation of vague malaise and back pain, a 52 year old woman was found to have an ESR of 110 $\mathrm{mm} /$ hour. A bone scan revealed a hot spot in the lumbar spine and radiographs showed marked destruction of the L3 and L4 vertebral bodies with loss of the L3/L4 disc space. Histology of large lymph glands, biopsied by a retroperitoneal approach, was non-specific. Tuberculosis was suspected and specific chemotherapy commenced. Her general malaise resolved and the ESR fell to $20 \mathrm{~mm} /$ hour after 6 weeks but low back pain persisted. Further radiographs revealed progressive vertebral collapse. A metal stabilising rod was inserted with immediate pain relief. Antituberculous chemotherapy was stopped after 12 months and the rod was removed. She has remained well and pain-free. Although a 


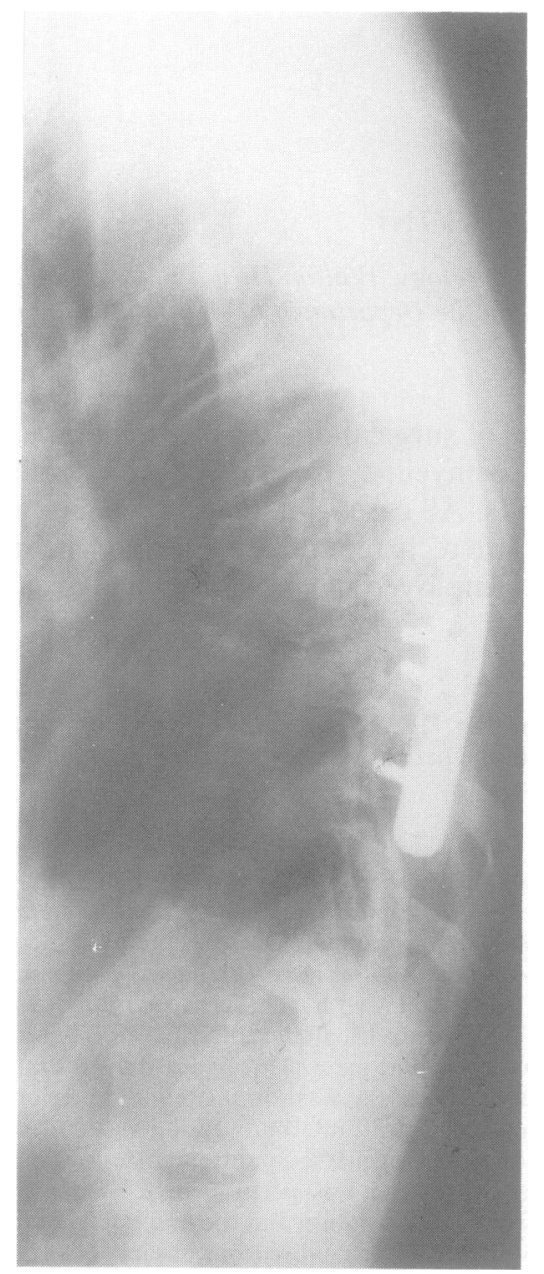

Fig 1 (Case 1) Lateral radiograph 6 months postoperatively showing satisfactory position of the prosthesis and a normal spinal curvature.

pathogen was never isolated, clinical and radiological evidence both suggested a diagnosis of spinal tuberculosis.

Case 4 A 77 year old woman complained of mechanicaltype back pain for several months. Radiographs showed erosion of the vertebral bodies of L3 and L4 with loss of the L3/4 disc space (fig 2). A Banks Dervin rod was inserted with resultant pain relief. Staphylococcus aureus was cultured and antibiotic therapy commenced. Wound healing was initially troublesome but eventually occurred satisfactorily. She remained pain-free and fully mobile 12 months later when radiographs showed satisfactory fusion (fig 3 ).

Case 5 A 74 year old man developed persistent back pain after recent staphylococcal septicaemia. He was gravely ill with dehydration and pneumonia. He had a tender dorsal kyphosis, flaccid paraplegia (of 3 days duration) and a T4 sensory level. Collapse and angulation at T6 was shown radiographically, with an anterior extradural block at $\mathrm{T} 4 / 5$ on

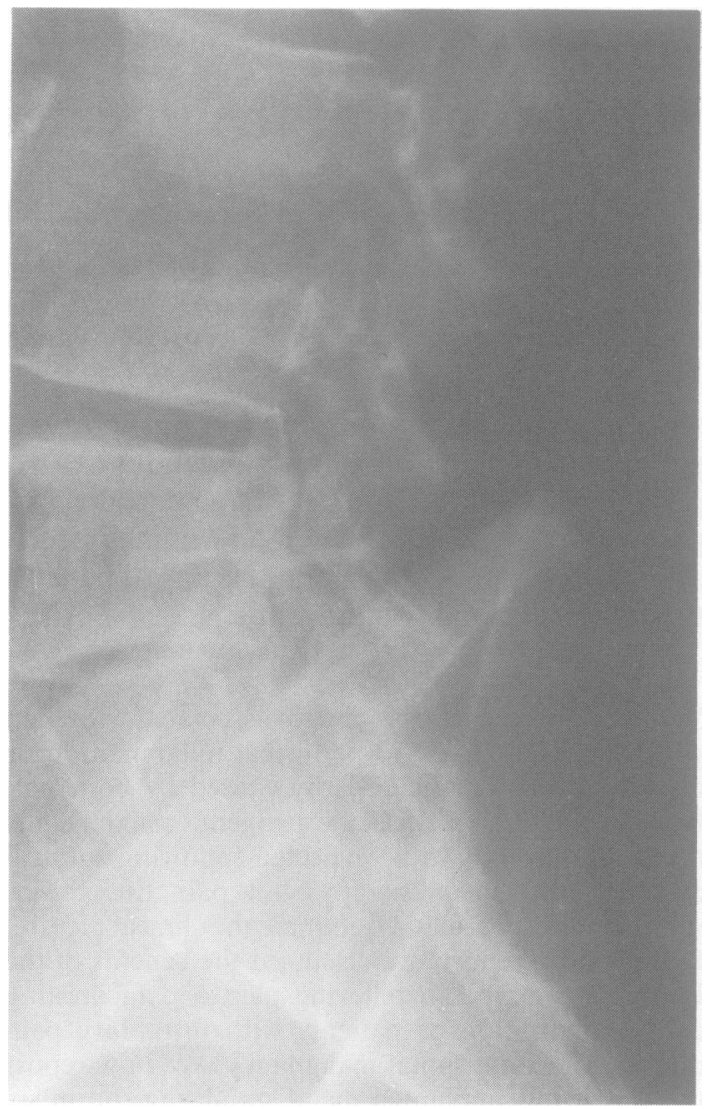

Fig 2 (Case 4) Preoperative lateral radiograph showing erosion of the vertebral bodies of L3 and L4 with loss of the intervening disc space.

myelography. An extradural abscess was drained through limited laminectomies at T5/6 and a posterior stabilising rod was inserted. Staphylococcus aureus was grown from the abscess. Postoperatively his general condition initially improved but no neurological recovery occurred. Respiratory movement was poor owing to the high thoracic spinal cord lesion and he developed recurrent pneumonia from which he died 25 days after surgery. Satisfactory wound healing was occurring and he had been pain-free.

Case 6 This 54 year old man developed lumbar discitis following staphylococcal septicaemia. Radiographs showed erosion of the L3/4 disc space and oral sodium fusidate and flucloxacillin were commenced. Four weeks later he suffered increasing low back pain and progressive weakness of the left leg. He also experienced thoracic instability pain with occasional electric shock-like sensations radiating from the costal margins to both legs. There was no spinal deformity but some tenderness in the lumbar region and a partial Brown-Séquard syndrome, with proximal left leg weakness and right T12 to S3 hypoaesthesia. Radiographs showed progression of the $L 3 / 4$ discitis with forward slip of L3 on L4. Lumbar myelography showed a complete anterior extradural block at T6/7 with loss of the disc space; the lumbar 


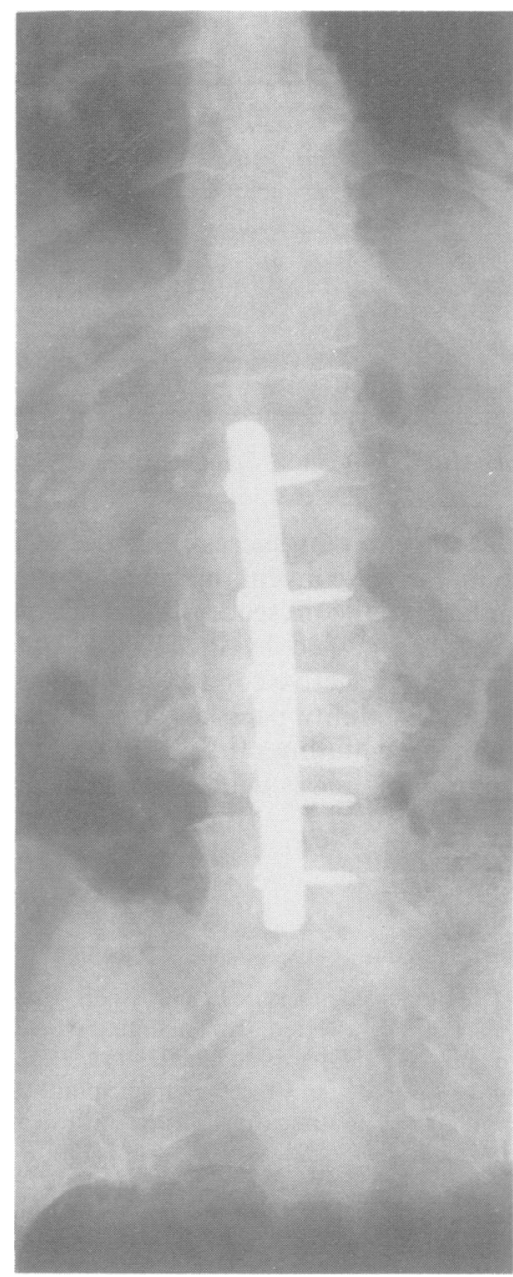

Fig 3 (Case 4) AP radiograph 12 months postoperatively showing fusion at L3/4 and satisfactory position of the prosthesis.

theca was normal. At cervical myelography contrast ran freely down to the proximal end of the block at T6. CT myelography confirmed an anterior extradural mass at T6/7. Laminectomies were performed at T6 and T7, and the pedicles were excised, particularly on the left side, to give access to the T6/7 intervertebral space from which soft bone and disc fragments were cleared. Although no frank pus was identified, the dura was oedematous and inflamed throughout the length of the exposure. After decompressing the dura, a Banks Dervin rod was inserted. Staphylococcus aureus was grown from the operative specimens and vancomycin was commenced. Following initial postoperative neurological improvement, weakness of the left triceps developed 4 days later and further radiographs showed destruction of the C6/7 disc space. This infection resolved with continued antibiotic therapy. Since multiple spinal levels were involved, and despite being pain-free, he was mobilised in a supportive spinal jacket. Twelve months after operation he was pain-free and fully mobile; there remained slight residual hypoaesthesia in the right $\mathrm{L} 2$ and L3 dermatomes.

\section{Discussion}

Historically, the treatment of spinal osteomyelitis involves surgical drainage of the abscess, removal of any sequestrated bone and disc, followed by appropriate antibiotic therapy and prolonged immobilisation. ${ }^{23}$ In the series of 100 cases of spinal tuberculosis reported by Hodgson and Stock ${ }^{3}$ the average length of postoperative immobilisation was 3 months and 12 days. Of 28 cases of pyogenic spinal osteomyelitis reported by Griffiths and Jones 16 were treated in plaster beds for an average period of 3 months. ${ }^{4}$ Although some authors advocate primary anterior spinal fusion with bone grafts, ${ }^{356}$ management protocols involving prolonged bed rest either alone ${ }^{78}$ or in combination with surgery ${ }^{3-11}$ persist owing to reluctance to use prosthetic implants for fear of perpetuating infection, compounded by previous lack of a suitable technique of stabilisation which would be reliable in the early postoperative period.

However, prolonged immobilisation carries serious risk of respiratory complications, thromboembolic disease and altered calcium metabolism causing osteoporosis, hypercalcaemia and urinary calculi. ${ }^{12}$ Rarely, fatal acute duodenal obstruction may occur due to the constrictive effect of abdominal splinting produced by a plaster-of-Paris cast. ${ }^{1314}$ Prolonged inpatient treatment may also produce psychological sequelae for patients and families, in addition to economic implications for health services and loss of income to the patient. With early mobilisation and ambulation many of these problems are avoided. Furthermore, the ability to sit up without pain soon after surgery facilitates nursing care and physiotherapy.

The efficacy of the Banks Dervin rod, ${ }^{1}$ and other similar internal stabilising devices, ${ }^{15}{ }^{16}$ in the management of patients with metastatic spinal malignancy, particularly in respect of early mobilisation and relief of pain, especially of the instability type, is widely recognised and accepted; in contrast, the use of such prostheses in the face of active spinal infection has received little support.

Recent orthopaedic experience has helped to establish the precedent for prosthetic implantation in the presence of infection. Not only have successful joint replacements been performed following healed septic and tuberculous arthritis ${ }^{17}$ but also cases of current or quiescent sepsis have been satisfactorily managed by primary joint replacement combined with appropriate antibiotic therapy. ${ }^{1819}$

Thus, where instability has been a prominent feature, in pyogenic or tuberculous spinal osteomyelitis, 
Table Clinical details of six patients with spinal osteomyelitis treated by surgical drainage and primary stabilisation with a Banks Dervin rod

\begin{tabular}{|c|c|c|c|c|c|c|c|c|c|c|}
\hline \multirow[b]{2}{*}{ Case } & \multicolumn{2}{|c|}{ Age/sex } & \multicolumn{2}{|c|}{ Pre-op } & \multirow[b]{2}{*}{ Spinal level } & \multirow[b]{2}{*}{ Organism } & \multicolumn{3}{|c|}{ Post-op response } & \multirow[b]{2}{*}{ Outcome } \\
\hline & $y r$ & $M / F$ & Pain & Para & & & Pain & Para & $\ln f$ & \\
\hline $\begin{array}{l}1 \\
2 \\
3 \\
4 \\
5\end{array}$ & $\begin{array}{l}20 \\
60 \\
52 \\
77 \\
74\end{array}$ & $\begin{array}{l}\mathbf{M} \\
\mathbf{M} \\
\mathrm{F} \\
\mathrm{F} \\
\mathbf{M}\end{array}$ & $\begin{array}{l}+ \\
+ \\
+ \\
+ \\
+\end{array}$ & $\begin{array}{l}+ \\
+ \\
- \\
+\end{array}$ & $\begin{array}{l}\text { T7/8 } \\
\text { T8/9 } \\
\text { L3/4 } \\
\text { L3/4 } \\
\text { T4/5 }\end{array}$ & $\begin{array}{l}\text { Myco. tb } \\
\text { E. coli } \\
\text { ? Myco. tb } \\
\text { Staph. aur } \\
\text { Staph. aur }\end{array}$ & $\begin{array}{l}- \\
\overline{-} \\
\overline{-} \\
-\end{array}$ & $\begin{array}{l}- \\
\overline{-} \\
\overline{+} \\
+\end{array}$ & $\begin{array}{l}\bar{z} \\
\bar{z} \\
-\end{array}$ & $\begin{array}{l}\text { excellent } \\
\text { died CCF at } 6 \text { months } \\
\text { excellent } \\
\text { excellent } \\
\text { died pneumonia at } 25 \\
\quad \text { days }\end{array}$ \\
\hline 6 & 54 & $\mathbf{M}$ & + & + & $\begin{array}{c}\text { T6/7 (L3/4) } \\
\text { (C6/7) }\end{array}$ & Staph. aur & - & - & - & excellent \\
\hline
\end{tabular}

Pre-op symptoms: Pain $+=$ instability type pain; Para $+=$ neurological deficit.

Post-op response: Pain $-=$ pain-free; Para $-=$ ambulant; Para $+=$ no neurological recovery; Inf $-=$ no recurrent infection.

Outcome: $\mathbf{C C F}=$ congestive cardiac failure.

posterior stabilisation has been performed at the same time as drainage of the abscess, followed by appropriate postoperative high-dose antibiotic chemotherapy. The clinical details are summarised in the table. In three of the four patients with preoperative neurological deficit marked functional improvement occurred; the fourth patient (case 5) had a complete flaccid paraplegia for three days prior to referral and no neurological recovery was observed. In one patient superficial infection resulted in delayed, but ultimately satisfactory wound healing; in all other cases wound healing was uneventful. All the patients had experienced instability pain preoperatively and this was relieved by stabilisation, thereby allowing early mobilisation in every case. In one patient in particular (case 2), a 60 year old man with chronic respiratory disease, prolonged bed-rest, combined with the difficulty of administering effective physiotherapy in the presence of posture-related pain, may well have proved fatal, whereas the freedom of movement engendered by operative fixation allowed nursing in the sitting position immediately after operation.

The use of intralaminar screws for fixation of the Banks Dervin rod avoids the potential risk of injury to neural elements within the spinal canal which accompanies methods of stabilisation involving sublaminar wiring; this is especially important in infective conditions when the extradural space may be compromised by inflammation. Furthermore, although undertaken in only one of these patients, it may be considered appropriate to remove the prosthesis after fusion has occurred, in which case the rod and screws can be safely retrieved without difficulty.

The relative absence of problems of wound healing in these cases may be due to the quality of modern antibiotic agents or to the high doses employed when therapeutic blood levels are monitored. Since the Banks Dervin rod is embedded in acrylic cement, current investigations into the place for antibioticimpregnated cement in cases of infected hip prostheses $^{20}$ are of interest.
It would appear that successful practice has dictated a change in the conventional attitude toward the use of implants in the presence of infection when advantage is to be gained by it. The use of a metal stabilising rod in infective conditions of the spine associated with instability pain has proved effective in relieving pain, facilitating nursing care and allowing early mobilisation, and is without obvious disadvantage.

\section{References}

1 Miles JB, Banks AJ, Dervin E, Noori ZF. Stabilisation of the spine affected by malignancy. $J$ Neurol Neurosurg Psychiatry 1984;47:897-904.

2 Hodgson AR, Stock FE. Anterior spinal fusion: a preliminary communication on the radical treatment of Pott's disease and Pott's paraplegia. Br J Surg 1956;44:266-75

3 Hodgson AR, Stock FE. Anterior spine fusion for the treatment of tuberculosis of the spine. $J$ Bone Joint Surg 1960;42-A:295-310.

4 Griffiths HED, Jones DM. Pyogenic infection of the spine: a review of twenty-eight cases. J Bone Joint Surg 1971;53-B:383-91.

5 Kemp HBS, Jackson JW, Jeremiah JD, Hall AJ. Pyogenic infections occurring primarily in intervertebral discs. J Bone Joint Surg 1973;55-B:698-714.

6 Kirkaldy-Willis WH, Thomas TG. Anterior approaches in the diagnosis and treatment of infections of the vertebral bodies. J Bone Joint Surg 1965;47-A:87-110.

7 Garcia A Jr, Grantham SA. Haematogenous pyogenic vertebral osteomyelitis. J Bone Joint Surg 1960;42-A: 429-36.

8 Henriques CQ. Osteomyelitis as a complication in urology. Br J Surg 1958;46:19-28.

9 Hallock H, Jones JB. Tuberculosis of the spine: an endresult study of the effects of the spine-fusion operation in a large number of patients. $J$ Bone Joint Surg 1954;36-A:219-40.

10 Pritchard AE, Robinson MP. Staphylococcal infection of the spine. Lancet 1961;ii:1165-6.

11 Medical Research Council Working Party on 
Tuberculosis of the Spine. A 10-year assessment of a controlled trial comparing debridement and anterior spinal fusion in the management of tuberculosis of the spine in patients on standard chemotherapy in Hong Kong. J Bone Joint Surg 1982;64-B:393-8.

12 Petersdorf RG, Adams RD, Braunwald E, Isselbacher KJ, Martin JB, Wilson JD, eds. Harrison's Principles of Internal Medicine (10th Ed.) New York: McGrawHill, 1983.

13 Schwartz DR, Wirka HW. The cast syndrome: a case report and discussion of the literature. $J$ Bone Joint Surg 1964;46-A:1549-52.

14 Berk RN, Coulson DB. The body cast syndrome. Radiology 1970;94:303-5.

15 Cusick JF, Larson SJ, Walsh PR, Steiner RE. Distraction rod stabilization in the treatment of metastatic carcinoma. $J$ Neurosurg 1983;59:861-6.

16 Sundaresan N, Galicich JH, Lane JM. Harrington rod stabilization for pathological fractures of the spine. $J$ Neurosurg 1984;60:282-6.

17 Hardinge K, Cleary J, Charnley Sir J. Low-friction arthroplasty for healed septic and tuberculous arthritis. J Bone Joint Surg 1979;61-B:144-7.

18 Jupiter JB, Karchmer AW, Lowell JD, Harris WH. Total hip arthroplasty in the treatment of adult hips with current or quiescent sepsis. J Bone Joint Surg 1981;63-A:194-200.

19 Wilson PD, Aglietti P, Salvati EA. Subacute sepsis of the hip treated by antibiotics and cemented prosthesis. $J$ Bone Joint Surg 1974;56-A:879-98.

20 Trippel SB. Antibiotic-impregnated cement in total joint arthroplasty. J Bone Joint Surg 1986;68-A:1297-302. 